\title{
A NEW GENUS OF FLEA-BEETLES FROM THE WEST INDIES*
}

\author{
By Doris H. Blake \\ Arlington, Va.
}

In 1868 Suffrian $^{1}$ described two species of small flea-beetles from Cuba which he placed under his section " $\mathrm{h}$ " of Haltica. with a suggestion that the legs were similar to those in the genus Aphthona of Chevrolat (which, incidentally, is not true). In the DeJean Catalogue ${ }^{2}$ are listed under Podagrica three names for one species from Santo Domingo, all nomina nuda, some of which names I have seen on old labels on specimens of this group in the Bowditch collection. In both cases the genus to which these beetles were more or less tentatively assigned was doubtless a matter of convenience, since they do not bear more than a superficial resemblance to the other species in either genus.

In addition to the two species carefully described by Suffrian from Cuba, and the ones named in the DeJean Catalogue from Santo Domingo, there exists an untold number of species of this group scattered on the various islands of the West Indies. Since they are all similarly colored, being yellowish or reddish with violaceous or blue-green elytra, and are minute beetles from 2-4 mm. long, up to the present they have been divided simply into two species-a bigger one (compressa) and a smaller one (auripennis) as described by Suffrian. Possibly it would be simpler to leave them as such, in the light of what dissection reveals.

As might be expected, there are certain resemblances to be found in the aedeagi of some of these beetles. A similar but somewhat different sort of aedeagus appears in some beetles on each island. Sometimes there are several very similar ones on the same island. This sort of similarity occurs in three groups composed of three or four species each. Besides these, there are

* Published with a grant from the Museum of Comparative Zoology at Harvard College.

${ }^{1}$ Suffrian, Archiv für Naturgesch., vol. 34, 1868, p. 211.

2 DeJean Catalogue, 1837 , p. 418. 
a number of other beetles with aedeagi that are widely unlike any other and that cannot be grouped with the rest or with each other. When I consider the relatively small number of specimens I have before me and the possibilities in the way of those that may be collected later in the West Indies, I realize how small a contribution to the genus I am able to give in my analysis of the few species (17) that I have studied. No one can distinguish these beetles from mere outward examination. Furthermore, it is not possible at present to identify Suffrian's two species with any degree of certainty. Even if the types are still in existence in the Museum at Halle, there is no certainty that any males are in the lot. Since the Gundlach collection of insects in Cuba, which contains specimens identified by Suffrian, is kept strictly under glass, little can be learned from it.

Maulik writes of Aphthona, "the genus being artificial is very difficult to define." Possibly he means that so many diverse species from all over the world are included under Aphthona that of necessity the group is far from homogeneous. It is true that the American species pigeon-holed with Aphthona do not altogether fit into the description of the European or Asiatic ones. For one thing, the elytra in many are striately punctate instead of confusedly punctate. Crotch described insolita Melsh., which is now referred to Aphthona, under the genus Cerataltica, as subquadrate in shape and striate-punctate. On the other hand, some of the species of Aphthona that Jacoby described from Central America seem closer to Jacoby's genus Palaeothona, which he described as "rather depressed, elongate and posteriorly widened," and with longer antennae and more transverse thorax. All these species need more study in order to determine their proper relationships. The West Indian group is unlike any of those that I have examined from the North American continent. In shape the beetles are generally broader and more convex than in Palaeothona and not at all subquadrate nor with striately punctate elytra as in the species related to insolita Melsh. The hind tibia, contrary to Suffrian's statement, is not like that in the European species of Aphthona, being rounded, not flat, and having a spur at the tip in the middle, not on the outside, and the claws are appendiculate, not 
simple. Since this group appears to be a sizable as well as homogeneous one and confined to the West Indies, I am proposing for it the generic name Homoschema, from ó $\mu$ ó the same, and $\sigma \chi \hat{\eta} \mu a(\tau o)$ outward appearance. The type of the genus is H. ornatum.

\section{Description of the Genus}

From $2-4 \mathrm{~mm}$. in length, oblong oval, widened posteriorly in female, moderately convex, often impunctate and at most very finely and confusedly punctate, lustrous reddish or yellowish with violaceous or blue-green elytra.

Antennae longer than half the body, always pale, rather stout; first joint long, 2nd short, both swollen, 3rd longer than 2nd, 4th longer than 3rd, the rest more or less subequal, gradually shortening a little. Head with distinctly marked frontal tubercles and an impressed line of punctures running up to the large fovea near the upper part of eye, a few scattered punctures usually in the space between eye and antennal sockets. Space between antennal sockets variable, in some narrower species a slightly elevated line gradually vanishing in the lower front, in other wider species, a broad, more convex carina that spreads out down the lower front with a depression on either side below the antennal sockets, this interantennal area very useful in identification as to the group but not to the species of the genus. Thorax considerably wider than long but never twice as wide, with curved and margined sides, and oblique angles anteriorly and almost straight basal margin; moderately convex without depressions, except in one species; surface usually mirror-smooth, sometimes very finely punctate. Scutellum large, triangular, and usually but not in all species, palely conspicuous in the dark violaceous elytra. The elytra often mirror-smooth or very finely and confusedly punctate, wider than the prothorax, convex, with a transverse depression below the humeri, the female usually slightly wider posteriorly. Beneath, the epipleura wide but disappearing at the apical angle. Body beneath usually pale, in a few species the breast and abdomen, and, in these cases, the scutellum too, dark. Legs and antennae always pale. Anterior coxal cavities open. Legs rather 
short and stout with the hind femora well developed. Tibiae not channelled or flat but rounded and with a short spur in the middle at the end of the hind tibiae. In the male the first joint of anterior tarsi enlarged and also in one species the first joint of the hind tarsi. In all, the first tarsal joint of the hind legs moderately long, in one species about equal to the following joints together. Claws appendiculate.

\section{Key to the Species of Homoschema}

1. Prothorax with a slight depression on either side near base; elytra deep violaceous with a pale yellowish tip. Haiti ...................... leucurum n. sp. Prothorax not at all depressed on either side near base; elytra dark without pale yellowish tip..........2

2. First tarsal joint of hind legs in male swollen, aedeagus long with a flat, roundish tip. Puerto Rico

H. latitarsum n. sp.

First tarsal joint of hind legs in male not swollen....3

3. Scutellum usually, and breast and abdomen always,

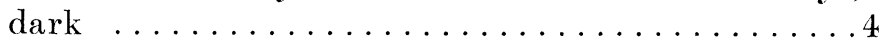

Scutellum, breast and abdomen pale........6

4. Aedeagus with a long attenuated tip. Haiti

H. hoffmani n. sp.

Aedeagus with a broad point at tip..........5

5. Aedeagus widened to approximately twice the width of tip behind the tip. Puerto Rico, St. Thomas, St. Croix..................... nigriventre n. sp. Aedeagus widened less than twice the width of tip behind the apex. Puerto Rico..........H. fraternum n. sp.

6. Beetles larger (3-4 mm.) and broadly convex; aedeagus broad with a short, acute tip........... Beetles not so large, aedeagus not so broad and not with a short acute tip.................

7. Aedeagus in dorsal view widened in a smooth curve behind the tip. Cuba................. latum n. sp. Aedeagus in dorsal view widened in a sinuous curve be-

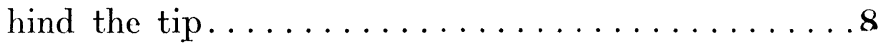


8. Aedeagi differing slightly in specimens from each island: Puerto Rico. See illustration.....H. obesum n. sp. St. Croix. See illustration............ pingue n. sp. Haiti. See illustration. . . . . . . . . o. opimum n. sp.

9. Aedeagus with a more or less acute tip, not broadly rounded .................10 Aedeagus not at all acute at tip but more or less

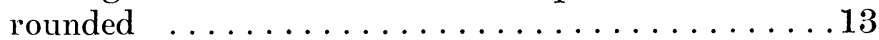

10. Aedeagus widened shortly behind apex to nearly twice width of apex.................11

Aedeagus more gradually widened behind apex . . . . 12

11. Aedeagus with complicated structure on dorsal side at tip, not readily described (see illustration). Cat Is. Bahamas ..................... felis n. sp. Aedeagus with complicated structure on dorsal side at tip, see illustration. Cuba.......... ornatum n. sp.

12. Beetle broadly convex. St. Francisco Mts., Dominican Republic .................... buscki n. sp. Beetle more slender, not very convex. Jamaica

H. jamaicense n. sp.

13. Aedeagus tapering to apex.............. Aedeagus narrowed before broad apex.......15

14. Median orificial plate curving slightly upward without any transverse carina. Guantanamo, Oriente Prov., Cuba..................... orientense n. sp. Median orificial plate apically strongly recurved and elevated. Coast below Pico Turquino, Oriente Prov., Cuba.................... darlingtoni n. sp.

15. Aedeagus shorter, broader, the subangular apex very obtuse with straight sides. Felton, Oriente Prov., Cuba.................... manni n. sp. Aedeagus narrower, apex rounded. Andros Is., Bahamas................... androsense n. sp.

Since all the species resemble each other closely in external appearance, and since the generic description is already given, only a short description with the few slight differences to be observed in each species is necessary. 
Homoschema hoffmani n. sp.

Fig. 10

From 2.5-3.2 mm. in length, 1.5-1.8 mm. in width, moderately convex, thorax and elytra smooth with fine punctation seen only under high magnification; antennae, head, thorax and legs reddish yellow, breast and abdomen dark, scutellum often dark, elytra violaceous. Area between antennal sockets moderately broad and convex, and extending down the short lower front, with a depression on either side below the antennal sockets.

Type.-Male, and 2 paratypes, U. S. N. M. Cat. No. 59192.

Type locality.-Bizoton, Haiti, Nov., 1925, collected on Stigmatophyllum lingulatum, by W. A. Hoffman.

Other localities.-Camp Perrin, W. A. Hoffman, 1925; Mt. 'Trou d'Eau, Nov., 1934, P. J. Darlington; Manneville, Nov. 16-17, 1934, P. J. Darlington; Cape Haitien, W. M. Mann: 'ort au Prince, all Haiti.

Remarks. - The distinguishing characters of this species are the dark coloring of the undersurface and the exceedingly long narrow point at the tip of the aedeagus, the latter unlike any other known in the genus.

\section{Homoschema leucurum n. sp.}

Fig. 12

From 2.7-3 mm. in length, 1.4-1.7 mm. in width, prothorax with a slight depression on either side at base; very faintly and finely punctate, reddish yellow with deep violaceous elytra having a pale apex. Head with a short elevated area between antennal sockets, lower front flattish.

Type.-Male, and 5 paratypes, U. S. N. M. Cat. No. 59193 ; 1 paratype in Museum of Comparative Zoology, Type No. 28238.

Type locality.-La Vanneau, Haiti, June, 1925, collected by W. A. Hoffman, on Bunchosia glandulosa.

Remarks.-This is the only one of the genus with a pale tip on the elytra. Another unusual feature is a slight depression on either side at the base of the prothorax. 
[Mar.

\section{Homoschema latitarsum n. sp.}

Fig. 15

From 3-3.5 mm. in length, $2.5 \mathrm{~mm}$. in width, broad, convex, very lustrous, not visibly punctate, reddish yellow with deep violaceous elytra, sometimes deep bronzy purple. Head with a narrow interantennal elevation extending from between antennal sockets halfway down to labrum. First tarsal joint of hind leg in the male broadened as is usually the case in the first tarsal joints of the anterior legs.

Type.-Male, and 1 paratype, Museum of Comparative Zoology Type No. $2823 \%$.

Type locality.-Maricao Forest, 2000-3000 ft. alt., Puerto Rico, collected May 31-June 2, 1938, by P. J. Darlington.

Other localities.-Yauco, June, 1934, by C. M. Matos, (Stuart T. Danforth coll.); Adjuntas, July, 1933 and June, 1934, by R. G. Oakley, both Puerto Rico.

Remarks.--The unusual feature about this species is the enlarged first tarsal joint of the hind leg in the male. 'The long aedeagus with the flat, rounded tip is also unlike any other in the genus.

\section{Homoschema ornatum n. sp.}

Fig. 1

From 2-3 mm. in length, 1.2-1.5 mm. in width, not very convex, finely punctate, reddish or yellowish with deep violaceous elytra. Head with a narrow elevation between antennal sockets and a short line from it down lower front. Lower front unusually long and flattish.

Type.-Male, and 5 paratypes, U. S. N. M. Cat. No. 59194, 2 paratypes in Museum of Comparative Zoology, Type No. 28242.

Type locality.-Cayamas, Cuba, collected by E. A. Schwar\% in February and March, also by C. F. Baker and George Dimmock in April.

Explanation of Plate 1

Fig. 1. Homoschema ornatum n. sp. Fig. 2. Homoschema felis n. sp. Fig. 3. Homoschema nigriventre n. sp. Fig. 4. Homoschema fraternum n. sp. Fig. j. Homoschema jamaicense n. sp. Fig. 6. Homoschema androsense $\mathrm{n}$. sp. Fig. 7. Homoschema darlingtoni n. sp. Fig. 8. Homoschema manni n. sp. Fig. 9. Homoschema orientense n. sp. 


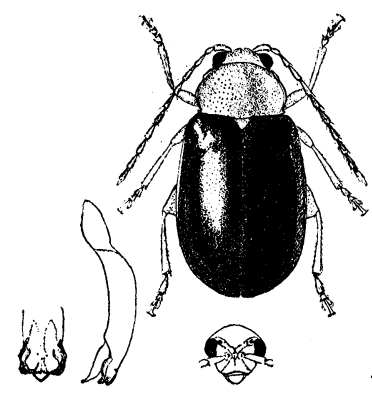

1. Homoschema ornatum

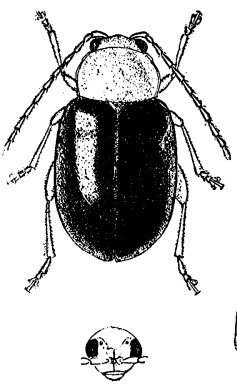

4. $\dot{H}$. fraternum

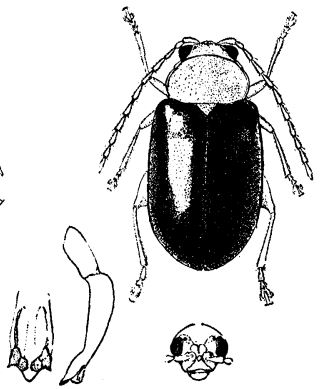

2. H. felis

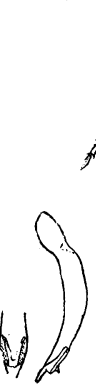

5. H. jarraicense

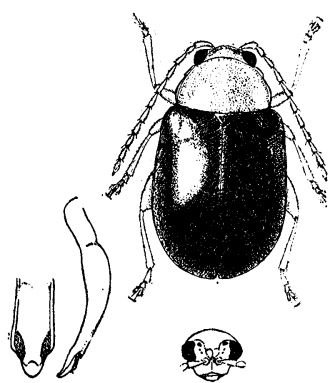

3. H. niqriventre

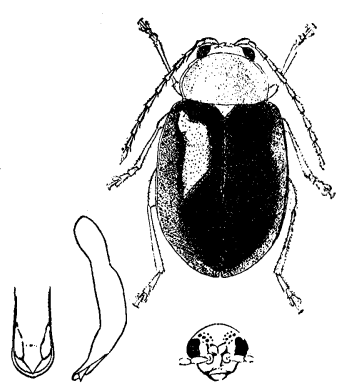

6.H. androsense

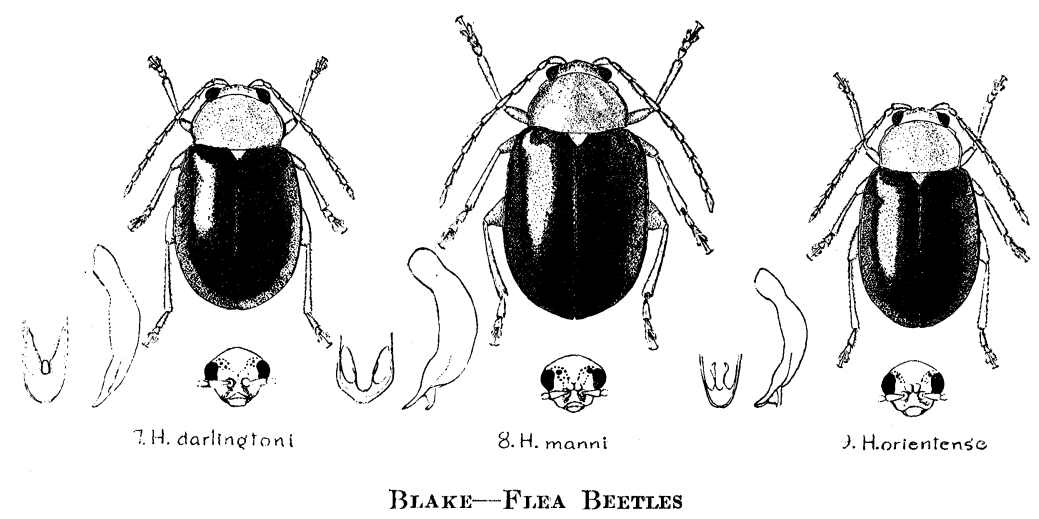


Remarks.-The relatively flat and distinctly punctate upper surface and the narrow aedeagus with a complex structure at the tip in the way of orificial plate distinguish this species. It belongs to a group that is represented in several other islands of the West Indies.

\section{Homoschema felis n. sp.}

Fig. 2

About $2.5 \mathrm{~mm}$. in length, $1.2 \mathrm{~mm}$. in width, not very convex, fincly punctate, reddish yellow with green elytra; head with a short, narrow elevation between antennal sockets and a line from it down lower front, lower front flat.

Type--Male, Museum of Comparative Zoology 'Type No. 28243.

Type locality.-Arthurs 'Town, Cat Island, Bahamas, collected July 10, 1935, by W. J. Clench.

Remarks.-This species is very closely related to H. ornatum, showing only a slight difference in the orificial plate of the aedeagus.

\section{Homoschema nigriventre $\mathrm{n}$. $\mathrm{sp}$.}

Fig. 3

From 2.5-3 mm. in length, $1.5 \mathrm{~mm}$. in width, moderately convex, finely punctate, reddish yellow with violaceous elytra and dark breast and abdomen. Head with a slight narrow elevation between antennal sockets and a line proceeding from this down lower front, lower front flattish.

Type.-Male, and 5 paratypes, U. S. N. M. Cat. No. 59195.

Type locality.-Ponce, Puerto Rico, collected Aug. 11, 1933, by R. G. Oakley.

Other localities. - Algarrobo, Feb., 1931, San German, Oct. 11, 193\%, Mayaguez, Sept., 1930, all in the Stuart T. Danforth collection; Parguera, Sept., 1933, on Colubrina; La Sardinera, June, 1939, W. A. Hoffman; Mona Island, April, 1940, on young shoot of Clusia rosea, L. F. Martorell; Rio Piedras, April, 1912, D. L. Van Dine; Manati, Feb., 1933, on leaf of Crotalaria: all Puerto Rico.

Remarks. - The dark breast and abdomen as well as its greater convexity separate this species from its close relatives, $H$. ornatum and $H$. felis. The head is not so long either. It has a 
similarly shaped aedeagus but with a less complex orificial plate. I am unable to separate a series of specimens taken on St. Croix by H. A. Beatty and another series taken on St. Thomas, V. I. collected in January, 193\%, in the Stuart T. Danforth collection, from this Puerto Rico species.

\section{Homoschema fraternum n. sp.}

Fig. 4

About $2.5 \mathrm{~mm}$. in length, $1.3 \mathrm{~mm}$. in width, not very convex, finely punctate, reddish yellow with violaceous elytra and dark breast and abdomen. Head with a slight narrow elevation between antennal sockets and a line running down the lower front, lower front flat.

Type.-Male, U. S. N. M. Cat. No. 59196.

Type locality.-San Juan, Puerto Rico, collected Oct. 13. 1932, by R. G. Oakley.

Remarks. - This single specimen differs from the others from Puerto Rico in having a narrower aedeagus with considerably less widening behind the tip. It belongs to the same group as $H$. ornatum and $H$. nigriventre, and like the latter is dark below.

\section{Homoschema jamaicense n. sp.}

Fig. 5

From 2.4-3 mm. in length, $1.5 \mathrm{~mm}$. in width, not very convex, elytra very finely punctate, yellow or reddish with violaceous elytra; head with a very narrow and short elevation between antennal sockets, and a line extending down in the lower front. Lower front flattish.

Type.-Male, and $\%$ paratypes, U. S. N. M. Cat. No. 5919\%; 1 paratype in Museum of Comparative Zoology, Type No. 28236.

Type locality.-Bath, parish of St. 'Thomas, Jamaica, collected Feb. 8, 193\%, by E. A. Chapin and R. E. Blackwelder.

Other localities.-Kingston, Balaclava, Jamaica, Feb. 13, collected by E. A. Chapin and R. E. Blackwelder.

Remarks.-This is the only Jamaican species thus far collected, and is a small, rather flat species with an aedeagus that 
is suggestive of that of $H$. nigriventre. It probably belongs to that group of species.

Homoschema buscki n. sp.

Fig. 11

From 2.5-3.2 mm. in length, $1.7-2 \mathrm{~mm}$. in width, convex, elytra very finely punctate; yellowish or reddish with violaceous clytra; interantennal area narrowly elevated and extending down a little in lower front, lower front flattish.

Type.-Male, and 6 paratypes, U. S. N. M. Cat. No. 59198.

Type locality.-S. Francisco Mts., Dominican Republic, collected Sept. 4-14, 1905, by August Busck.

Other localities.-Blanton mine, north of San Cristobal, Dominican Republic, July 26, 1917, Harold Morrison, collector.

Remarks.-The convex elytra and the long, gradually acuminate aedeagus unlike any other in this group, distinguish this species. It is not closely related to the group that follows, which is also composed of large convex species.

\section{Homoschema latum n. sp.}

Fig. 16

About $3 \mathrm{~mm}$. in length, $1.6 \mathrm{~mm}$. in width, convex, elytra very faintly and finely punctate, reddish or yellowish with violaceous elytra. Head with interantennal area convex and extending down in lower front, a depression on either side below antennal sockets.

Type-Male, U. S. N. M. Cat. No. 59199.

Type locality.-Upper Yara Valley, Cuba, collected Oct. 18, 1928 , on weeds and grasses by I. C. Scaramuzza.

Remarks.- The broad, convex elytra and the short, wide aedeagus distinguish this species. It is closely related to the three following species from Haiti, Puerto Rico and St. Croix,

Explanation of Prate 2

Fig. 10. Homoschema hoffmani n. sp. Fig. 11. Homoschema buscki n. sp.

Fig. 12. Homoschema leucurum n. sp. Fig. 13. Homoschema pingue n. sp. Fig. 14. Homoschema opimum n. sp. Fig. 15. Homoschema latitarsum n. sp. Fig. 16. Homoschema latum n. sp. Fig. 17. Homoschema obesum n. sp. 

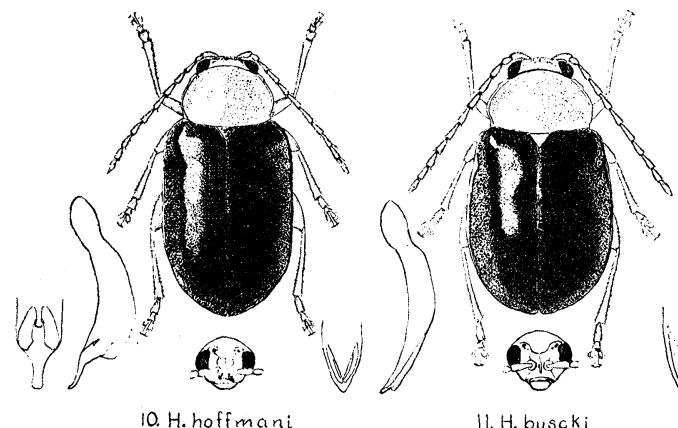

11. H. buscki
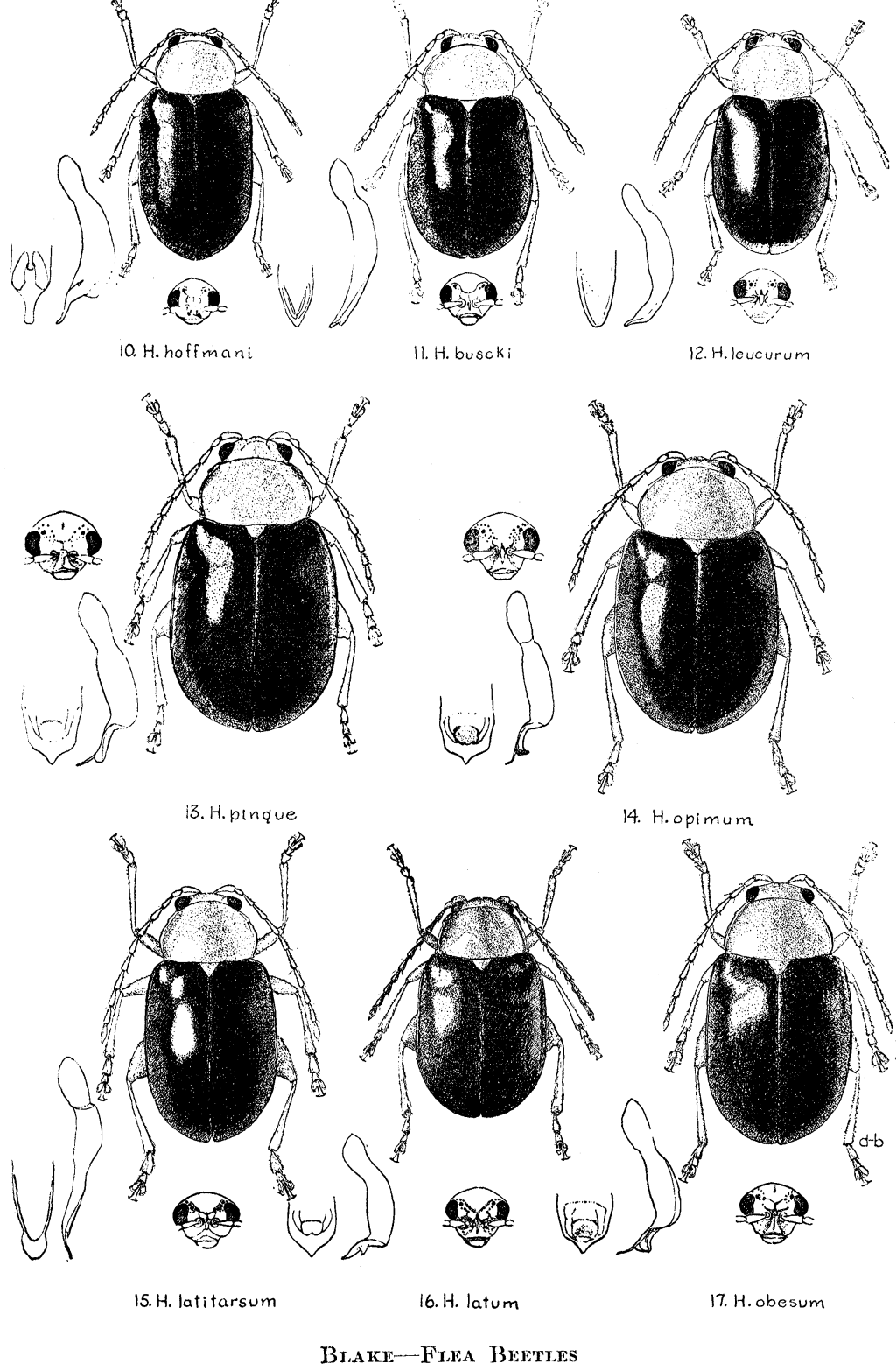
but not so closely to them as they are to each other. From the one specimen seen, it would seem to be slightly smaller and has a differently shaped apex on the aedeagus.

\section{Homoschema obesum n. sp.}

Fig. 17

From 3.2-4 mm. in length, 2-2.8 mm. in width, convex, elytra very faintly and finely punctate, reddish or yellowish with violaceous elytra. Head with an interantennal area broadly convex and extending down the lower front, depressed below the antennal sockets.

Type.--Male, and 8 paratypes, U. S. N. M. Cat. No. 59200 ; 1 paratype in Museum of Comparative Zoology, Type No. 28239 .

Type locality.-El Vigia, Ponce, Puerto Rico, collected on a vine by R. G. Oakley, July 26, 1934.

Other localities. - Yauco, March 28, 1929, Mayaguez, Feb. 24, 1925, Algarrobo, Feb. 2\%, 1931, Boqueron, April 18, 1924, all from Puerto Rico, in the Stuart 'T. Danforth collection.

Remarks.-This is one of the largest species of the genus and very closely related to the two following from St. Croix and Haiti. It has a short broad acdeagus very similar to that of Er. latum but with a more sinuate apex.

\section{Homoschema pingue n. sp.}

Fig. 13

From 3.2-4 mm. in length, 2-2.8 mm. in width, convex, very taintly and finely punctate, reddish or yellowish with violaceous elytra; head with a broad median convex area from between antennal sockets extending down lower front with a depression below antennal sockets.

Type.-Male, and 1 paratype Museum of Comparative Zoologr Type No. 28240; 1 paratype in U. S. N. M. Cat. No. 59201.

Type locality.-St. Croix, V. I., H. A. Beatty collector, also collected there by H. Morrison June 14, $191 \%$.

Remarks.-This is very closely related to $H$. obesum from 
Puerto Rico, showing only a slight difference in the tip of the aedeagus.

\section{Homoschema opimum n. sp.}

Fig. 14

From 3.3-4 mm. in length, 2.1-2.4 mm. in width, convex, very faintly and finely punctate, reddish or yellowish with violaceous sometimes even deep bronzy purple elytra; head with a broad median interantennal convexity extending down front and a depression on either side below antennal sockets.

Type.-Male, and 2 paratypes, Museum of Comparative Zoology Type No. 28241.

Type locality.-San Jose de las Matas, Dominican Republic, 1000-2000 ft. alt., collected in June, 1938, by P. J. Darlington.

Other localities.-Macoris, March 30, 1913, P. G. Russell; S. Francisco Mts., April 9, 1905, August Busck; Duarte, Domingo City, July 21, 191\%, H. Morrison, all Dominican Republic. Poste Terre Rouge, Oct. 5, 1934, P. J. Darlington; Cape Haitien, W. M. Mann; Port au Prince, April, 1925, G. N. Wolcott; La Vanneau, June 20, and Bizoton, Nov. 25, on Stigmatophyllum lingulatum, both by W. A. Hoffman, all Haiti.

Remarks.- This is the fourth of the group and closely related to the Puerto Rico and St. Croix species with only a little difference in the aedeagus. The frontal convexity on the head seems a little narrower and less convex.

\section{Homoschema orientense n. sp.}

Fig. 9

From 2.4-2.9 mm. in length, 1.4-1.7 mm. in width, convex, distinctly punctate, reddish yellow with violaceous elytra. Head with a broad interantennal elevation extending down the short lower front.

Type.-Male, and 8 paratypes, U. S. N. M. Cat. No. 59202; 1 paratype in Museum of Comparative Zoology, Type No. 28245.

Type locality.-Guantanamo, Cuba, collected in 1918 by W. M. Mann.

Remarks.-The only way of distinguishing this from the following species is by comparing the aedeagi. In this species the aedeagus is narrowed towards the apex, instead of being 
broader near the apex than behind it. The distinct punctation of the elytra distinguishes this from H. latum.

\section{Homoschema manni n. sp.}

Fig. 8

From 2.5-3 mm. in length, 1.5-1.7 mm. in width, convex, with distinctly punctate elytra, reddish yellow with violaceous elytra. Head with a moderately broad interantennal area extending down the front and slightly elevated.

Type.-Male, and 2 paratypes, U. S. N. M. Cat. No. 59203, 1 paratype in Museum of Comparative Zoology, Type No. 28244 .

Type locality.-Felton (Oriente Province on Antilla Bay), Cuba, collected by W. M. Mann.

Other localities. - Cayamas, Cuba, E. A. Schwarz, Bah. Honda, Cuba, in June by H. F. Wickham.

Remarks.-Like the preceding species this is distinctly punctate. The shape of the aedeagus separates it from its close relative, $H$. orientense.

\section{Homoschema darlingtoni n. sp.}

Fig. 7

From 2.4-2.8 mm. in length, 1.3-1.5 mm. in width, moderately convex, without distinct punctures, reddish yellow with violaceous elytra. Head with a rather broad interantennal area elevated between antennal sockets and extending down the short lower front.

Type.-Male, and 1 paratype, Museum of Comparative Zoology, 'Type No. 28246; 1 paratype in U. S. N. M. Cat. No. 59204 .

Type locality.-Coast below Pico 'Turquino, collected June 26-30, 1936, by P. J. Darlington.

Remarks.-This species although closely related to $H$. orientense and $H$. manni, differs in not having visibly punctate elytra. It has a shorter frontal elevation on the head. The aedeagus is not so broad as in manni and broader than in orientense with a strongly recurved orificial plate. 


\section{Homoschema androsense n. sp.}

Fig. 6

From 2.5-3 mm. in length, 1.5-1.8 mm. in width, convex, distinctly punctate, reddish yellow with violaceous elytra. Head with a short, broad, elevated interantennal area that extends down the lower front.

Type.-Male, and 1 paratype, Museum of Comparative Zoology Type No. $2824 \%$.

Type locality. - Andros Island, Bahamas, collected Aug. 1-10, 1904, by "Barber" (? Barbour).

Remarks. - The distinctly punctate and convex elytra and the broadly rounded apex on the aedeagus place this species very near $H$. manni. 'The area between the antennal sockets of the head is short and broad as in H.darlingtoni. 

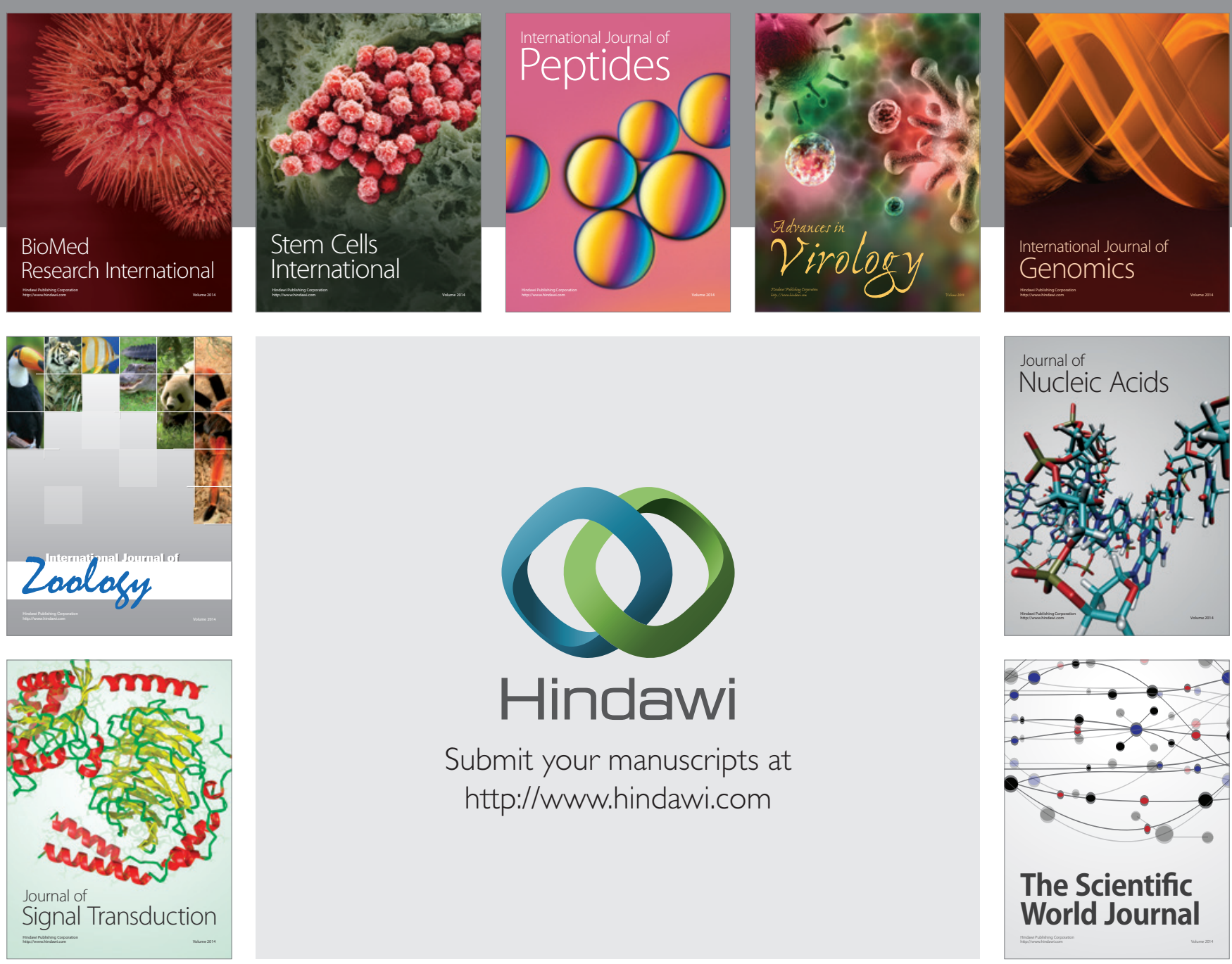

Submit your manuscripts at

http://www.hindawi.com
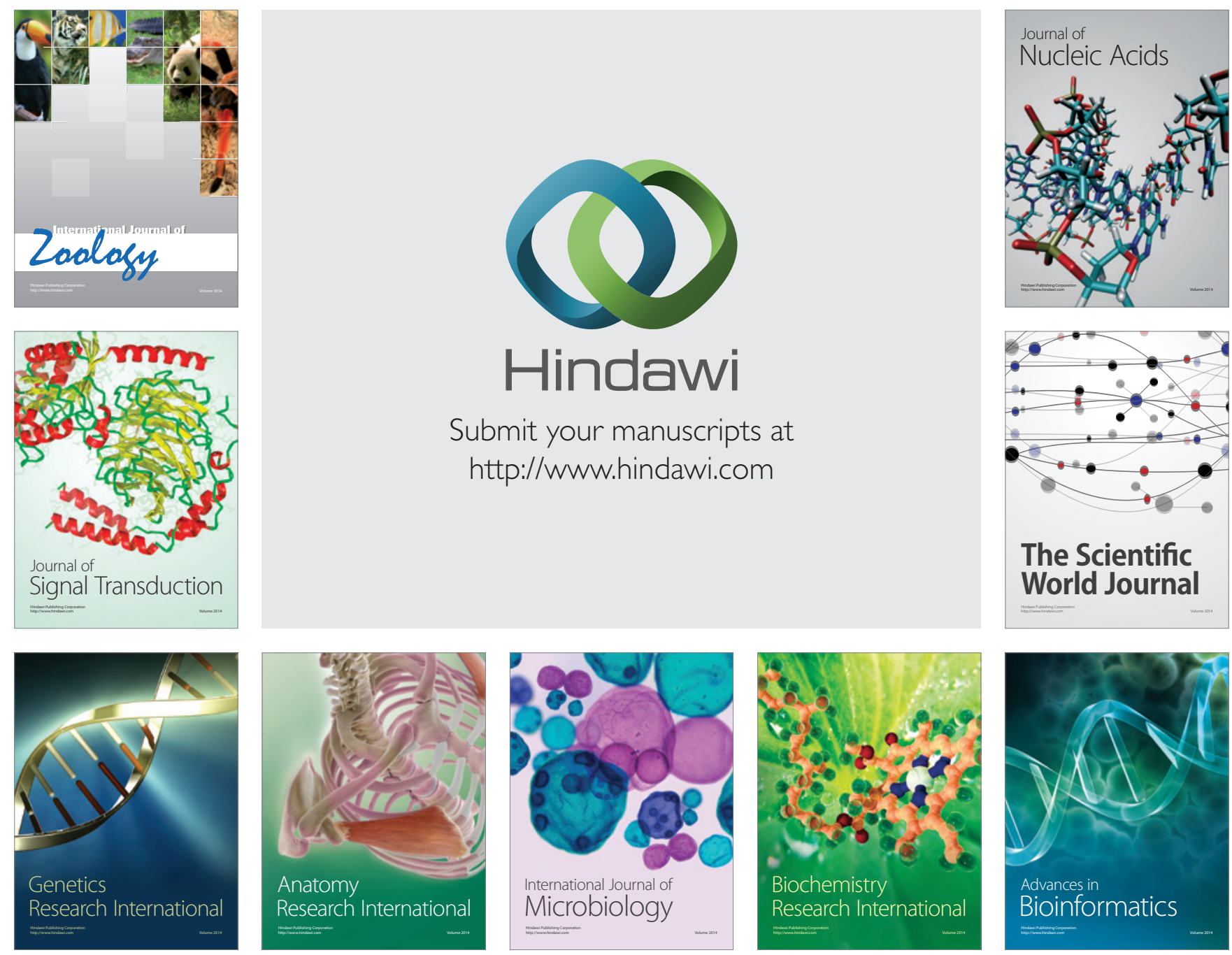

The Scientific World Journal
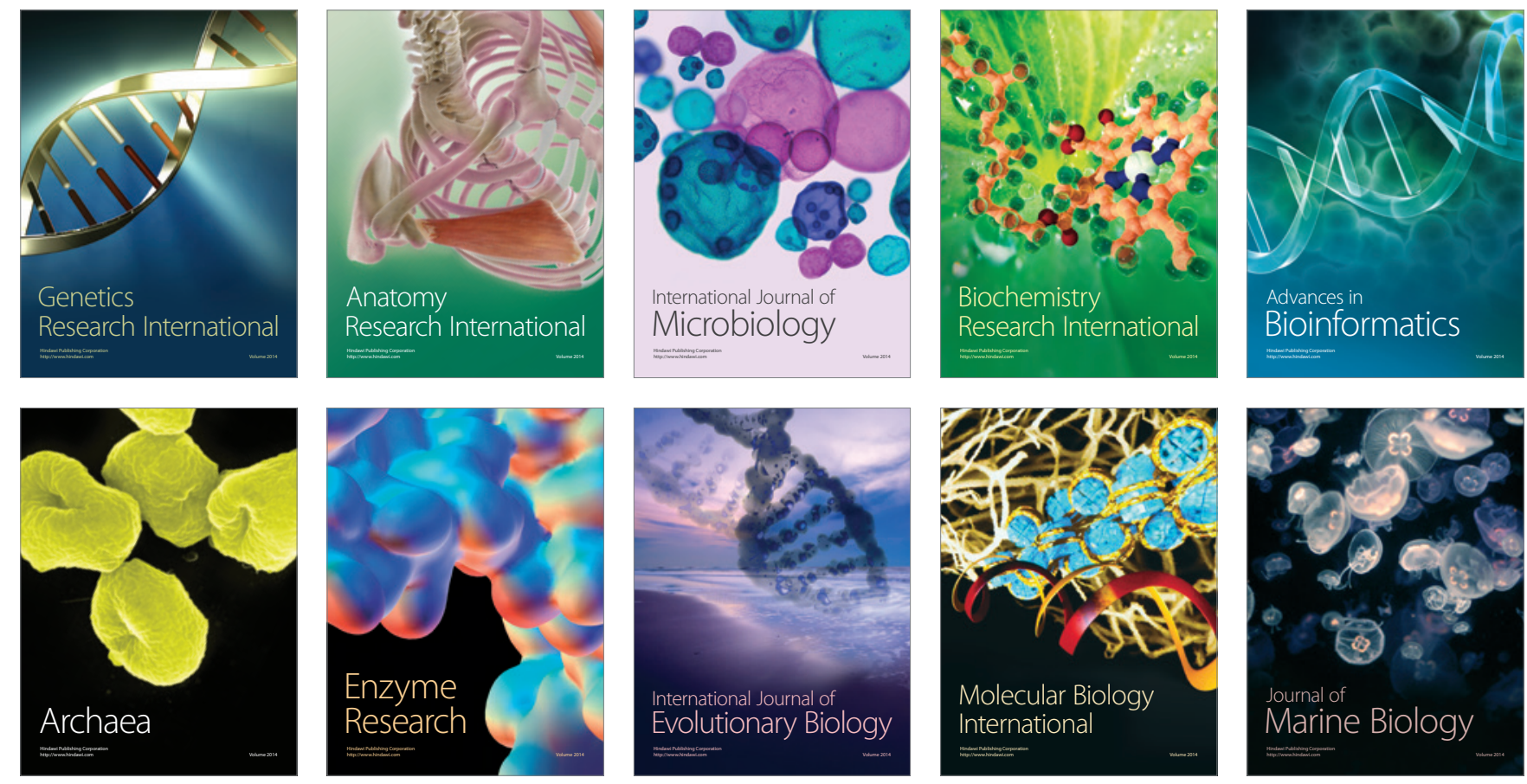